\title{
LA CONSTRUCCIÓN DE LAS LINDES DE LA OCEANÍA HISPANA: ESTEREOTIPOS QUE TRASPASAN LA FRONTERA PARA REVALORIZAR LOS ESTUDIOS DEL PACÍFICO
}

\section{THE CONSTRUCTION OF THE BOUNDARIES OF HISPANIC OCEANIA: CROSS BOUNDARY STEREOTYPES TO REASSESS STUDIES ON THE PACIFIC.}

\author{
David Manzano Cosano \\ Escuela de Estudios Hispano-Americanos
}

CSIC

\section{RESUMEN}

España no se preocupó de delimitar las fronteras del territorio dependiente del gobierno de Manila hasta el siglo XIX cuando se produjo un creciente interés del sistema internacional por el Pacífico. En los últimos años se ha avanzado en la integración de la historiografía española en los Estudios del Pacífico y evidenciar cómo los estereotipos que crean las grandes potencias sobre este océano son determinantes en la política española a la hora de delimitar las fronteras de la denominada Oceanía hispana. El uso de las fuentes cartográficas y su relación con la política exterior hispana serán otro aspecto novedoso de esta investigación.

Palabras clave: Oceanía Hispana, Océano Pacífico, Polinesia, Melanesia, Micronesia

\begin{abstract}
Spain was not concerned with delimiting the boundaries of the territory dependent on the government in Manila until the nineteenth century, when the international community began to take a growing interest in the Pacific. In recent years, advances have been made with regard to integrating Spanish historiography in studies of the Pacific and these demonstrate how stereotypes which the major powers created were a determining factor in Spanish politics when it came to delimiting the boundaries of so-called Hispanic Oceania. Other original aspects of this research include the use of cartographic sources and their relation to Hispanic foreign policy.
\end{abstract}

Keywords: Hispanic Oceania, Pacific Ocean, Polynesia, Melanesia, Micronesia 


\section{INTRODUCCIÓN}

El pasado 13 de febrero de 2015 el autor de este artículo presentó en la Universidad Complutense de Madrid la tesis titulada España en el Pacífico: la construcción de las fronteras filipinas en la Oceanía hispana contemporánea, 1789-1900 bajo la dirección de Salvador Bernabéu y Florentino Rodao. Ante el afán de esta tesis de potenciar los estudios del Pacífico para el caso de la España contemporánea, sus parámetros cronológicos están determinados por la historia colonial hispana de esta época. Por tanto, se inicia en 1789, por los efectos que el estallido de la Revolución francesa produjeron en la Península y en el sistema internacional -como indica que los teóricos de las Relaciones Internacionales sitúen en el triunfo de estos movimientos liberales el inicio de un nuevo orden mundial (PEREIRA, 2009; PEARSON, 2000; BARBE, 2007)-; y se concluirá con el convenio de 7 de noviembre de 1900, por el que España vendió a Estados Unidos las islas de Sibutu y Cagayán de Joló, desprendiéndose de todos sus derechos en sus colonias ultramarinas (OLIVART, 1897, p. 173). Por la amplitud temporal que abarca el trabajo, éste está dividido en tres bloques definidos por el cambio de la política exterior hispana en la defensa de sus fronteras en la Mar del Sur. A continuación, se presentarán de una forma somera los mismos para que el lector conozca el contenido de la investigación que fundamentan las aportaciones historiográficas sobre las que versa este este artículo.

Los bloques han sido creados acogiendo los postulados kantianos (MURILLO, 2005) que resaltan el papel del individuo en la sociedad mundial para definir a los Estados (que constituirán los actores primordiales del análisis del sistema mundial del trabajo) como "contenedores sociales" (BECK, 1998) dirigidos por un conjunto de hombres. En tanto y cuanto, estos responden a pautas psicológicas y sociológicas, el comportamiento de España en el sistema internacional podrá ser analizado desde el prisma de estas Ciencias porque las acciones que este actor estatal efectúa son fruto de las decisiones de las personas que formaban el ejecutivo gubernamental. De ahí, que se haya recurrido a las teorías de la psicología del desarrollo del individuo para delimitar los bloques, que clasifican la evolución de la conducta de la política exterior española en la defensa de sus fronteras en la Oceanía hispana. 
El primero de ellos se titula "La etapa de transición del Imperio de Ultramar, 1789-1828". En él se analiza el cambio de un nuevo orden internacional en el Pacífico producido por el fin del "Lago Español" dominado por el Galeón de Manila (SPATE, 1979; SCHURZ, 1922). Para ello, se definen cuáles fueron aquellos "charcos" de poder hispanos que constituyeron este "lago" moderno, para comprender de forma más clarividente cómo España protege sus territorios de las potencias que avanzan por la Oceanía, las cuales hacen uso de sus comerciantes y misioneros para conseguir el objetivo de dominar una determinada área. Su presencia, unida al desarrollo de las expediciones científicas de descubrimiento y el inicio de la carrera colonizadora en este espacio con la integración de Nueva Holanda a la estructura administrativa británica, alterará la geopolítica de la Mar del Sur, obligando a los políticos hispanos a variar los viejos parámetros del periodo moderno que concebían este espacio bajo el protagonismo de la $\mathrm{Nao}$ de China, y asumir que se había concluido su hegemonía en la región. De este modo, asistimos a un periodo de transición del Pacífico por la necesidad de la clase hispana de remodelar las estructuras administrativas en sus colonias. De ahí, que se concluya este primer bloque con el Informe Ricafort (1828)' que pretende reformar el sistema de las Marianas a los nuevos tiempos, al advertirse en sus objetivos la conceptualización contemporánea del Pacífico donde se asume el fin del Galeón de Manila.

La asunción de esta realidad que hace desaparecer el "Lago español", condicionará que el Estado ibérico cree una nueva forma de relacionarse con el Pacífico y con sus fronteras, de modo que adoptará una nueva identidad, que tildaremos de hipotecada, siguiendo las tesis de James Marcia (ERIKSON, 1968; BRIONES, 2000, pp. 33-34). Pues España, como si fuera uno de los adolescentes analizados por este psicólogo (a quienes califica así por autodefinirse y marcar sus objetivos vitales por la influencia de valores ajenos), definirá sus señas de identidad en sus territorios limítrofes en el Pacífico por la influencia y preponderancia de las potencias. De esta forma, se titula el segundo bloque de la tesis: "España y su tendencia a la identidad hipotecada en las fronteras oceánicas, 1828-1885", porque su política exterior en la región, dominada por el conflicto internacional de Joló-Borneo, estará definida por la pasividad y la tendencia a no enfrentarse a los Imperios que se aproximan a las Filipinas, para evitar nuevos problemas internacionales. Estas potencias se aproximan al archipiélago por la proliferación de los denominados tratados desiguales y por la reva-

1 NAP (National Archives of Philippines), Varias Provincias, Marianas, SDS 4341, 1826-1861, expediente 1. 
lorización del Pacífico. Dicho valor será asumido por la sociedad española, al popularizarse el término "Oceanía hispana" para defender los derechos de su nación en la cuenca oeste de este océano. Este segundo bloque se extenderá hasta el conflicto de las Carolinas de 1885, cuando el país ibérico abandonará su pasividad característica con la cual había abordado la cuestión de Borneo y alzará su voz contra Alemania para reclamar sus derechos en estas islas.

Por tanto, el tercer y último bloque abarcará apenas 15 años (18851900). Sin embargo, será el más voluminoso debido a que, como consecuencia de la importancia que el colonialismo adquiere en el nuevo sistema internacional, la metrópoli española aumentará su preocupación por el territorio limítrofe de la Oceanía hispana y, por tanto multiplicará las medidas políticas, que fomentarán el acercamiento del pensamiento peninsular a estas latitudes. Estas medidas pondrán de manifiesto la debilidad del Imperio. Pues sus proyectos para desarrollar sus nuevas colonias fronterizas no podrá llevarlos a cabo por sus precarios recursos, que destinará para alejar de sus centros colonias a las grandes potencias y no para explotar el territorio. En este bloque, la región de las Carolinas tendrá una mención especial para compensar la escasez de trabajos de la historiografía española dedicadas a esta área. Tras analizar la producción literaria y cartográfica para hallar los estereotipos creados por la ciudadanía española con respecto a la Micronesia, rescataremos las actas inéditas de la ocupación efectiva de España en sus islas menores y terminaremos nuestro estudio señalando de qué forma se produce el fin de la historia colonial de España en el Pacífico. Así nos detendremos en el análisis diplomático de este proceso para desmontar las tesis sobre la permanencia de derechos soberanos en la Micronesia creada por $\mathrm{E}$. Pastor durante el régimen franquista, que aún algunos españoles de la sociedad del siglo XXI siguen defendiendo. ${ }^{2}$

A la luz de la exposición puede apreciarse que una de las señas de identidad de esta investigación es su objetivo de analizar el juego del poder que se produce en la sociedad internacional del siglo XIX y focalizar su atención en la relación que las potencias decimonónicas establecen en el Pacífico, escogiendo a España como estudio de caso. Estamos por tanto en una investigación interdisciplinar entre la Ciencias Políticas y la Historia que se detiene en la región fronteriza de la Oceanía hispana, muy poco estudiada en la historiografía española; que pretende analizar la política exterior

2 MIRANDA, Isabel, "Las islas españolas del Pacífico y otros territorios olvidados de nuestro país", En ABC, 1-9-2013, http://www.abc.es/España/20130901/abci-territorios-espanoles-olvidados-201308302122. html . 
hispánica más allá de España; y que se esfuerza en asumir la metodología una corriente científica prácticamente desconocida en la historiografía española como son los Estudios del Pacífico.

\section{La preocupación por la marginal Micronesia: La defensa del concepto de Oceanía hispana.}

En 1992, la doctora $M^{a}$ Dolores Elizalde publicó España en el Pacífico: la colonia de las islas Carolinas, 1885-1899, monográfico que se ha convertido en el referente más importante para estudiar las colonias contemporáneas más distantes del Imperio de ultramar español. El trabajo objeto de este artículo quiere continuar el camino abierto por esta autora para estudiar los confines de la denominada Oceanía hispana en la Micronesia contemporánea. De esta manera, pretendemos poner en valor esta región que sufre la marginación de la historiografía española como muestra que se defina al conjunto de los territorios que dependieron del gobierno de Manila como hispano-asia (LUQUE, 2007), en cuya conceptualización geográfica a priori no se englobaría los territorios oceánicos de Marianas y Carolinas.

Precisamente, para intentar salvar este olvido esta investigación apuesta por definir a la circunscripción filipina bajo el término de Oceanía hispana. Con ello, retomaremos un concepto que adquirió una gran popularidad entre la ciudadanía española de la segunda mitad del siglo XIX con el que se referían a sus colonias en el Pacífico. Con él nos referiremos a las islas que se engloban dentro de los archipiélagos de Filipinas, Marianas y Carolinas (incluidas las Palaos). Sobre este último grupo se debe efectuar una aclaración relacionada con la tendencia de las obras hispanas a diferenciar las Palaos de las Carolinas. El análisis de su discurso y el estudio de la división administrativa de la España ultramarina nos indican que se trata de una redundancia (como muestra que las Palaos fuesen integradas en la circunscripción de las Carolinas Occidentales) (COELLO, 1852). El origen de esta redundancia se halla en el desconocimiento de esta región, que la Corona hispana pensó por primera vez colonizar a finales del siglo XVII con la llegada de los náufragos desconocidos que arribaron a Samar (Filipinas). ${ }^{3}$ Tras fracasar la obra misional de Cantova, el olvido y marginación de esta área por parte de la mencionada monarquía, serán los causantes de la incapacidad de los españoles para diferenciar estas dos entidades

3 Lopez Museum (Manila), Filipiniana Collection, SERRANO, A., Noticias de las Palaos, 1705. 
geográficas, ${ }^{4}$ que extendieron el término Carolinas para designar a todo este amplio territorio del corazón de la Micronesia. ${ }^{5}$

Por otro lado, en el siglo XIX se divulga el vocablo Oceanía por parte de los geógrafos españoles, de esta forma asumen la nueva teoría con la que el mundo galo comenzará a definir al Pacífico, tras desarrollarse las expediciones científicas de finales del siglo XVIII y principios del siglo XIX. Será precisamente uno de sus marinos, Dumont d'Urville, quien pronuncie una conferencia en enero de 1832 para parcelar este gran océano en las regiones de Melanesia, Micronesia, Polinesia y Malasia, que adquirió una fama mundial que aún perdura. ${ }^{6} \mathrm{~A}$ pesar de que ninguno de estos términos fue acuñado por este explorador francés (TCHERKÉZOFF, 2003) ${ }^{7}$ y de que su mapa no fue el primero que delimitó en este sentido la Oceanía (RIENZI, 1814), su papel será clave para que la ciencia geográfica española acoja esta división gracias a su prestigio internacional. ${ }^{8}$ Mas, si comparamos en otras fuentes coetáneas las fronteras de las entidades geográficas popularizadas por d'Urville, apreciaremos el fenómeno que ya se plasma en la obra del otro gran erudito francés que fomentó esta delimitación de la Oceanía,

4 El informe de la expedición del Velasco de abril de 1885 (que será determinante para que España ocupe las Carolinas) refleja esta tendencia, debido a que afirma erróneamente que el padre Cantova descubrió las Palaos el 2 de marzo de 1731; Archivo Museo Naval, 0358, MS. 0079. Informe escrito por el capitán de fragata Felipe Cangas-Argüelles, Cavite 7 de junio de 1885, p. 11.

5 Esta tendencia se plasma en el documento cartográfico de referencia relativo a la Oceanía de mediados del siglo XIX: el mapa de Francisco Coello publicado en 1852. En él define a las Carolinas Occidentales como sinónimo de las Palaos, COELLO, F., "Posesiones de Oceanía,1852" [Cartografía], http://biblioteca.vam.es/cartoteca/cartdigitalcoello.html.

6 En la actualidad parte de su teoría sigue siendo secundada por un número significativo de cartógrafos (BIER, 2009)

7 El origen del concepto de Melanesia se halla en la obra de Bory de Sain-Vicent L'homme, essai zoologique sur le genre humain (Paris, 1832); el término de Polinesia fue sugerido por Charles de Brosses en 1756 tras la publicación de Historie des navigations aux Terres Australes...; y el de Micronesia por Domeny di Reinzi en una conferencia que pronunció en la Conferencia de la Sociedad geográfica de Paris en 1831.

8 En 1844 ya la Gaceta de Madrid acoge dicha división y en la segunda mitad del siglo XIX las obras geográficas hispanas siguen las teorías de Dumont d'Urville; Gaceta de Madrid, núm. 3406, de 11/01/1844, p. 4, http://www.boe.es/datos/pdfs/BOE/1844/3406/A0000400004.pdf. 
Grégory Domeny di Rienzi`: la falta de un consenso para fijar los límites de estos entes. La razón de ello se halla en la fragilidad de los fundamentos epistemológicos del navegante francés, pues apoya su segmentación en principios raciales, al dividir la Mar del Sur según el pigmento de la piel de sus habitantes. ${ }^{10}$ Cada tez la asociará a una determinada capacidad inte-

\section{Mapa 1}

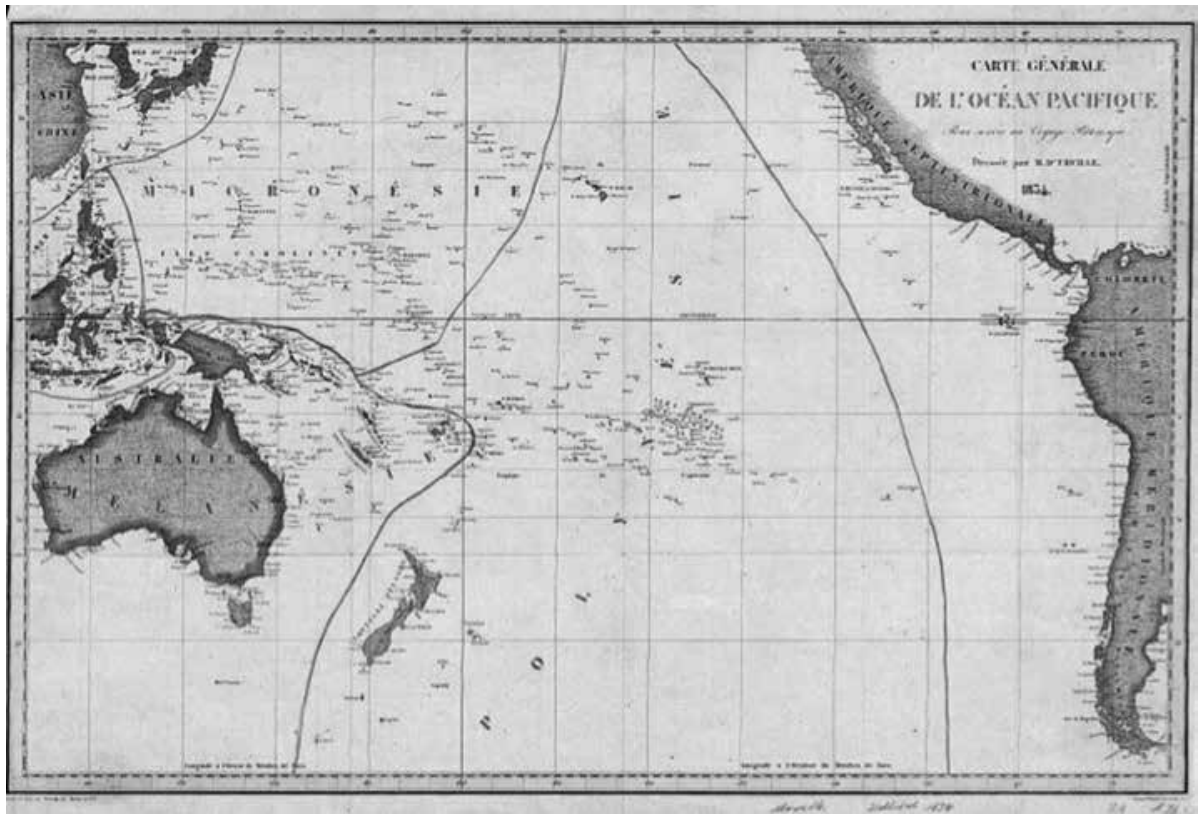

National Library of Australia, DUMONT D'URVILLE, Jules Sébastien César, Carte générale de I'Océan Pacific : pour servir au voyage Pittoresque autour du monde: résume général des voyages de découvertes de Magellan, Tasman, Dampier... Paris, Tenré, 1834- 1835, http://nla.gov. au/nla.map-rm651.

9 Antes que d'Urville presentará el 16 de diciembre de 1831 una conferencia en el seno de la Sociedad Geográfica de París donde dividirá la Oceanía en tres partes. Posteriormente, replicará la división de este navegante francés en su obra, RIENZI, di G.L.D., Historia de la Oceanía o quinta parte del Mundo. Barcelona, Imprenta del Fomento, 1845. [ $1^{\circ}$ edición 1836-1837].

10 Las tesis de J. R. Foster (quien navegará con el capitán Cook entre 1773-1775) y Charles de Brosses (1756) será crucial para que d'Urville divida el Pacífico en dos razas. La primera se caracterizará por su acercamiento a la raza europea (aunque según su criterio será de inferior categoría) albergando a los polinesios, micronesios y malayos. La segunda raza por su color negro estará constituida por los melanesios y, por consiguiente (dados los tintes racistas de su teoría) serán los que estarán dotados de menores capacidades. 
lectual, construyendo una pirámide social en cuya base situará a aquellos individuos más negros (melanesios) y en su cúspide ubicará a los polinesios (que tienen en su piel una mayor blancura que los micronesios y malayos).

Esta mixtificación de la realidad va a conducir a que se repruebe la terminología de d'Urville una vez que se consolide la historia del Pacífico como rama científica y se defienda la perspectiva del aborigen en su configuración. Estas críticas se avivarán en los años setenta del siglo XX hasta el punto de que se acuñe otra nueva estructuración del Pacífico que trate de salvar el prisma "occidental" mediante la diferenciación de la Cercana y Remota Oceanía (GREEN, 1991)." A pesar de que esta nueva parcelación haya sido bien acogida por diferentes científicos de distintas disciplinas (tales como la arqueología, antropología, zoología, botánica, etc.), y de que se defienda la necesidad de formar entidades geográficas menores para poder estudiar más apropiadamente los fenómenos que se circunscriben a esta área (ARCY, 2003), el peso de la historia colonizadora en el Pacífico ha provocado que la fragmentación de d'Urville aún siga en vigor en la actualidad (DOUGLAS, 1979; THOMAS, 1989). ${ }^{12}$ La falta de consenso para estructurar geográficamente este océano viene dada también por su complejidad, fruto de la heterogeneidad de realidades que esconde en su seno (MATSUDA, 2006). Así, la noción de este gran océano dependerá del propio investigador, quien se creará su particular esquema mental del territorio que pretende analizar en función de su contexto, metodología y temática de estudio (WOODWARD, 1998). Por tanto, estos mapas cognitivos son fabricados bajo criterios políticos subjetivos (LEWIS, 1997), ${ }^{13}$ hecho que conducirá a Robert Borofsky a criticar la construcción artificial del Pacífico:

"We need to remember that the field's self-defined area of study-the 'Pacific' - is a constructed artifact of the discipline. Why, for example, should Pacific historians study large Pacific islands such as New Zealand and New Guinea but ignore the Philippines and Indone-

11 Las nuevas entidades geográficas son acuñadas en 1973 por Andrew Pawley. La existencia de altas montañas y gran vegetación será la seña de identidad de la Oceanía cercana, mientras que la Oceanía remota se distinguirá por albergar ínsulas de pequeña magnitud y archipiélagos muy distantes entre sí.

12 Así lo prueba también la enciclopedia virtual más divulgada actualmente (www.wikipedia.es).

13 Estos autores sostienen que los entes geográficos adquieren el título convencional por parte de la Ciencia mediante el acuerdo de los expertos. 
sia?"(Why is Australia in some an accounts but not in others?). For those living in Hawai'i, the 'Pacific' refers to the islands lying within 'Melanesia,' 'Polynesia,' and 'Micronesia' (constructed categories themselves). For others on the West Coast of the United States, the 'Pacific' usually includes the Pacific rim -China, Japan, and Korea". (BOROFSKY, 2000, p. 25)

En relación con la temática de estudio del autor de este artículo, en esta cita habría que cuestionarse por qué los grandes científicos internacionales especialistas en la Oceanía excluyen a las Filipinas y siguen la teoría de Wallace qque en el siglo XIX marcó una línea para separar los continentes de Asia y Oceanía que atraviesa el archipiélago malayo, atendiendo a criterios biogeográficos) (WALLACE, 1869), a pesar de que su exclusión limita la comprensión de la evolución política de la Micronesia por su relación con el gobierno colonial de Manila. Ello podría estar motivado por el papel que juega la historiografía española a la hora de conceptualizar este gran océano bajo la perspectiva del "Spanish Lake" de Schurz (1922),14 cuya teoría exalta sus márgenes (Asia y América) para marginar a las islas del seno de la Mar del Sur. De ahí que sean escasos los estudios de las instituciones científicas españolas que ahondan sobre la historia de estos archipiélagos de forma autónoma (ELIZALDE, 2006), como advierte el estudio cualitativo y cuantitativo de las conferencias presentadas en el Congreso Internacional El Pacífico, 1513-2013. De la Mar del Sur a la construcción de un nuevo escenario oceánico (celebrado en Sevilla, en septiembre de 2013) donde ningún historiador español presentó una ponencia que ahondase de forma autónoma en la historia colonial de los Estados que actualmente se integran en la Oceanía y que cuentan con un gran peso en la estructura internacional, como podría ser el caso de Australia. Ante esta marginación, los centros de referencia de los Estudios del Pacífico han postergado el papel de España en la construcción de las señas de identidad de este gran océano para la época contemporánea. Ello se debe al sesgo etnocentrista que suele caracterizar la historiografía nacional de cada Estado y al gran protagonismo que los científicos españoles han otorgado al territorio filipino en la comprensión de la historia colonial hispana en el Pacífico contemporáneo. Un espacio que han conceptualizado dentro del continente asiático, de ahí, que se relegue a un segundo plano la participación hispana en los fenómenos oceánicos abordados por los estudios del Pacífico.

14 Su término se popularizó con la obra de SPATE, O.H.K, The Spanish Lake, 1979. 
Por esta marginación, que queda reflejada en el término de "hispano-asia" empleado por la escuela de Leoncio Cabrero para aludir a la historia de las colonias españolas en el Pacífico "occidental", este autor recupera el concepto de la Oceanía hispana para resaltar las islas de la Micronesia dentro de la circunscripción filipina.

Mapa 2

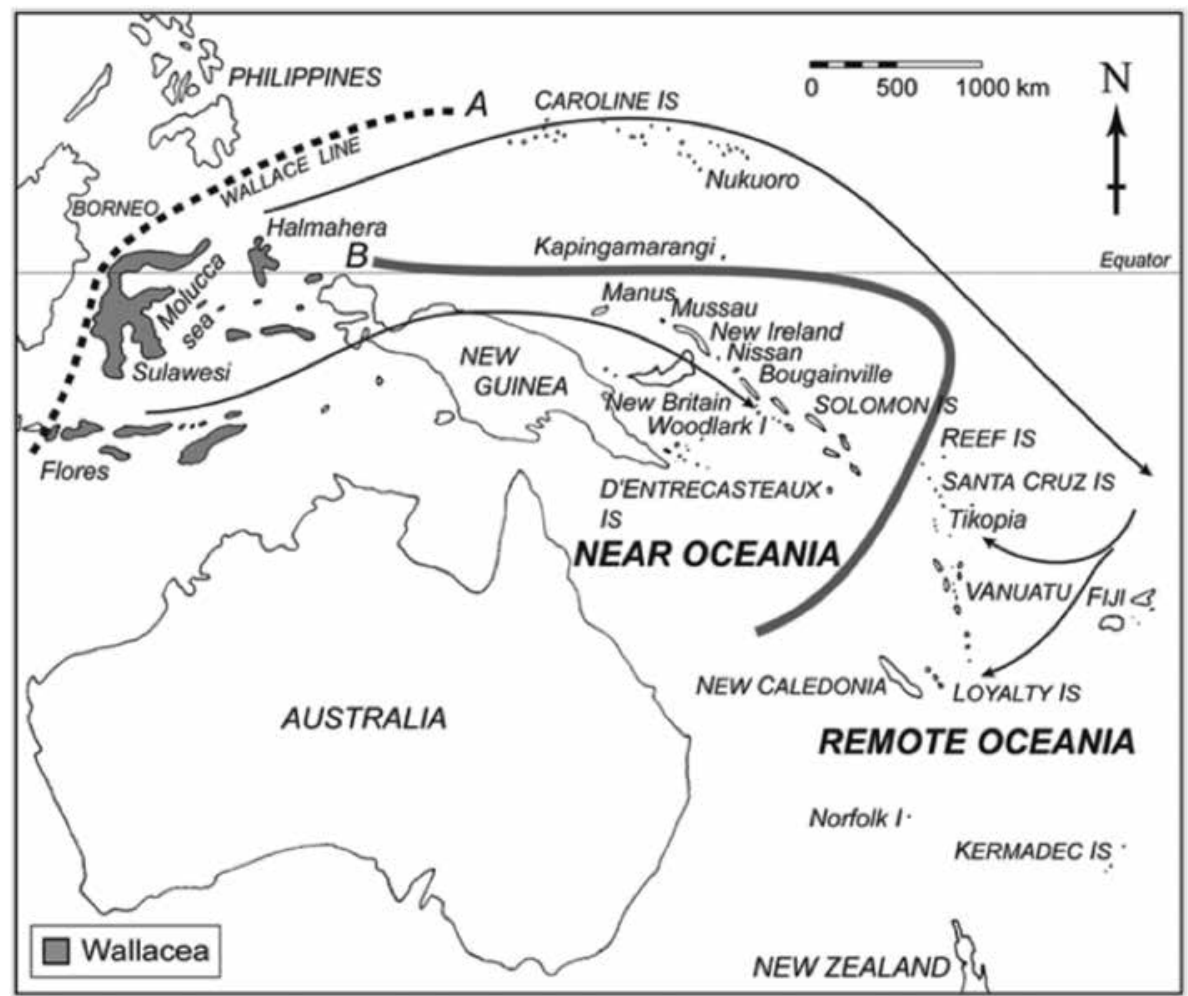

MATISOON-SMITH, E. et ROBINS, J.H, "Origins and Dispersal of Pacific People: Evidence from mtDNA phylogenies of the Pacific rat", en Proceeding of National Academy of Sciences of the United States of America (PNAS), Cl, n²4, 2004. pp. 9167-9172, http://www.pnas.org/content/101/24/9167/F1.large.jpg.

\section{Una perspectiva global de Relaciones Internacionales que va más allá DE LAS FRONTERAS ESPAÑOLAS Y LA DIPLOMACIA}

Siguiendo el debate del giro cultural que ha acogido en su seno la historiografía de las Relaciones Internacionales (GIENOW-HECHT,2003; NINKOVICH, 1989; NIÑO, 2009) -en la línea de aquellas teorías que pre- 
tenden la "desnaturalización de la nación" (LINDSAY, 2012)- y en nuestra búsqueda de los factores que inciden en la generación de los estereotipos del Pacífico traspasaremos el "contenedor social" del Estado español, en una doble dirección. Por un lado, por primera vez la historiografía española se detendrá en analizar de forma pormenorizada cuáles son las relaciones de poder que las potencias establecen en el heterogéneo seno del Pacífco contemporáneo (Australia, Hawai'i, Tahití, islas Salomón, etc...), para observar de qué forma estas dinámicas afectan a la política española en su circunscripción filipina. Y por otro lado, siguiendo las investigaciones de Matt Matsuda, indagaremos sobre el peso de los estereotipos en la política exterior española en el Pacífico. Por consiguiente, analizaremos el "contenedor social" de la sociedad hispana decimonónica desde una perspectiva global (examinando la influencia de las potencias en España para que defina su política exterior en el Pacífico) y desde su sustrato (observando la influencia de la opinión pública española en el ejecutivo español que determina la fisionomía de la Oceanía hispana).

Ulrick Beck popularizó el concepto de "contenedor social" para aludir al conjunto de los individuos que se engloban dentro del ente estatal, arguyendo que el fenómeno globalizador ha mermado la fuerza estatal para regir a los individuos que existen en su seno, al crearse vínculos y espacios sociales trasnacionales que escapan de su control (BECK, 1998, p. 36). Aunque es cierto que para la época de nuestro estudio la dimensión de la sociedad mundial no había adquirido las dimensiones del siglo XXI, ésta existía, como muestra la influencia del pensamiento europeo en la mentalidad del español decimonónico, que crea movimientos artísticos con unas características similares en países distantes. En este sentido, entendemos que al igual que existe un "contenedor social" estatal, existe "contenedor social" global, donde gracias al juego de poder del sistema internacional habrá un grupo de actores que posee una posición predominante para consolidar una ideología en la identidad grupal de dicha comunidad. Bajo estas premisas, consideramos el sistema internacional un sujeto homologable al Estado, en el sentido de que en el seno de este sistema se crea una sociedad con los oligarcas de las teorías de Pareto, Michels y Mosca, que crearán unos mecanismos de control donde su pensamiento será clave para forjar una identidad grupal mundial. Dada la complejidad para analizar a cada uno de sus integrantes esta obra acoge el prisma realista, al considerar a los Estados como una institución que representa a un conjunto de ciudadanos que han depositado en este ente sus intereses para alcanzarlos en la sociedad global.

En este marco, para acercarnos al imaginario que la ciudadanía hispana elabora sobre las fronteras filipinas analizaremos en primer lugar la 
relación de las grandes potencias, deteniéndonos en sus relaciones en el Pacífico, y de forma particular en el espacio que España incluye dentro de su órbita de influencia, para comprender cómo los agentes de las potencias generan un pensamiento relativo a este área. A continuación, exploraremos cómo esas imágenes son acogidas por la élite hispana, y por último de qué manera estas llegan al conjunto de sus compatriotas, mediante la creación de obras artísticas y literarias (DUBY, 1988; GOFF, 1985) relativas a las colonias hispanas de la Mar del Sur. En este punto, a tenor de la importancia de las imágenes visuales del pensamiento de Peter Burke, mostraremos una especial atención a la representación cartográfica de los límites de la Oceanía hispana. Un material de trabajo a resaltar debido a que no se suele utilizar en el análisis de la Historia de las Relaciones Interculturales. La relación de estas fuentes con la información consultada en los archivos visitados, donde destacamos los legajos relativos a las Marianas y Carolinas del National Archives of Philippines de Manila, nos ha permitido catalogar muchos de los mapas que no albergaban ningún tipo de pista sobre su contexto.

Por tanto, las citadas áreas fronterizas de la Micronesia y del archipiélago filipino serán los espacios centrales de esta investigación. Sin embargo, el actor primordial de este estudio se hallará en Europa, al estar constituidos por los españoles que con sus opiniones construyeron un imaginario colectivo sobre los puntos del Pacífico que estaban integrados dentro de la estructura estatal de su Estado. La tendencia a categorizar al "otro" condicionará el surgimiento de una serie de estereotipos. Unos juicios sesgados sobre la realidad que ayudarán a consolidar la identidad grupal de una comunidad, como advierten los estudios sociológicos de E. Cashmore, quien indaga sobre el concepto de "chivo expiatorio" (CASHMORE, 1996);15 o Robert E. Park, quien sostiene que los prejuicios que envuelven a los estereotipos son un signo de conservadurismo de los grupos dominantes, que temen que los cambios sociales que se producen en el seno de la sociedad provoquen la reducción de sus privilegios). Esta teoría constata la existencia de grupos de individuos que disfrutan de un poder de influencia mayor que otros a la hora de construir el pensamiento colectivo de la comunidad de la que forman parte. Asumiendo esta idea y siguiendo la línea de las teorías de la superestructura marxista de Louis Althusser, que inciden en la importancia de las élites en la construcción de la ideología nacional, se focaliza la atención sobre este segmento poblacional porque lo es crucial para que la masa

15 En sociología este término es empleado para definir el proceso por el cual un individuo traspasa las responsabilidades de sus desgracias y frustraciones a otros grupos que suelen minorías fácilmente identificables con escaso poder social. 
hispana interiorice como real un producto social (BERGER, 1966; MURGIA, 2002), que en este trabajo lo constituirían las imágenes del Pacífico.

Por la importancia de este océano asumiremos la metodología de los denominados estudios del Pacífico. Esta disciplina científica surgió a raíz de la conceptualización de Fernand Braudel del Mediterráneo como unidad histórica (1949), cuyos postulados adoptó Douglas L. Oliver para el caso del gran océano mundial al publicar Las Islas del Pacífico (1951). Con esta obra, se inauguraba una nueva corriente, que fue reforzada en los años cincuenta y sesenta del siglo XX con los trabajos de J.W. Davidson y A. Moorehead, y consolidada en los años setenta gracias a las investigaciones de Deryck Scarr, Ernest Dodge, Glen Barclay o Oskar Spate. Actualmente, la producción de las universidades estadounidenses (donde destaca Hawai'i), de Fiii, de Australia y de Nueva Zelanda convierte al mundo anglosajón como líder de este tipo de estudios, con investigadores como Matt Matsuda, David A. Chapp.ell, , Alison Bashford, Rainer Buschmann, etc., quienes han indagado sobre la historia colonial de este océano (MATSUDA, 2006).

La investigación de la que se ocupa este artículo, por su afán de analizar las visiones hispánicas de la Oceanía decimonónica, podría ser considerada como una especie de continuación cronológica del objeto de estudio de las investigaciones de Buschmann, quien ha indagado sobre este aspecto para la época moderna (BUSCHMANN, 2014). Ambas investigaciones acogen la idea de la "trans-localidad" impulsada por Matsuda (MATSUDA, 2010; ARMITAGE, 2013; IGLER, 2013), entendida como el pensamiento que se tiene de un punto por la relación que los diversos actores han generado sobre el lugar. Un pensamiento que puede ser utilizado en clave imperial, como demuestra dicho autor en Empire of love (2005), donde deja patente como la Francia decimonónica desarrolló el colonialismo en el Pacífico por la influencia de un imaginario colectivo sesgado, que estimuló el "amor" de una sociedad por querer dominar este espacio, a pesar de no conocer profundamente su realidad. Esta perspectiva de asumir desde un prisma de la Historia global esa idea de "translocalidad" del Pacífico contemporáneo va a hacer una de las principales aportaciones historiográfica de este estudio, el cual pretende analizar en qué medida el pensamiento de la sociedad hispana de comienzos de la contemporaneidad va a influir en las acciones que su Estado emprenden en el marco oceánico.

\section{Conclusiones}

La absorción de las principales aportaciones que los Estudios del Pacífico están dando a la Historia global y el estudio pormenorizado de las desconocidas áreas fronterizas de la Oceanía hispana contemporánea po- 
drían ser consideradas como la principal novedad que este estudio aporta al debate historiográfico español. Una investigación donde constantemente se apela a la relación interdisciplinar entre las Ciencias como prueba que se haya utilizado las fuentes literarias, normativas o cartográfica para ahondar en las imágenes que los españoles construyeron del Pacífico contemporáneo.

\section{Biblografía}

ARMITAGE, David et BASFORD, Alison (edit), Pacific Histories: Ocean, Land, People. New York, Palgrave, 2013.

ARCY, Paul D', "Cultural division and islands environments since the time of Dumont d'Urville". En The Journal of Pacific History, XXXVIII, $n^{\circ}$ 2,Taylor \& Francis, 2003, pp. 217-235.

BARBÉ, E., Relaciones Internacionales. Madrid, Tecnos, 2007 ( $3^{\circ}$ Edición). BECK, Ulrick. ¿Qué es la globalización? Falacias del globalismo, respuesta a la globalización. Barcelona, Paidós, 1998.

BERGER, P. L et LUCKMANN, T., The social construction of reality. A treatise in the sociology of Knowledge. New York, Doubleday, 1966.

BIER, James, A, Reference Map of Oceania: The Pacific Islands of Micronesia, Polynesia, Melanesia. Honolulu, University of Hawa'i Press, 2009 [2 Edit.].

BOROFSKY, Robert (edit), Remembrance of Pacific Pasts: An Invitation to Remake History. Honolulu, University of Hawai'i Press, 2000.

BRAUDEL, Fernad, La Méditerranée et le Monde Méditerranéen a l'époque de Philipp.e II, París, Armad Colin, 1949.

BRIONES PÉREZ, Elena, La aculturación de los adolescentes inmigrantes en España: aproximación teórica y empírica a su identidad cultural y adaptación psicosocial. Salamanca, Universidad de Salamanca, 2010,

BUSCHMANN, Rainer, Iberian Visions of the Pacific Ocean, 1507-1899. Palgrave, 2014.

BUSCMANN, R., SLACK, E. et TUELLER, J.B., Navigating the Spanish Lake: The Pacific in the Iberian World, 1521-1898. Hawai'l, University Hawai'i, 2014.

BURKE, P., Visto y no visto: los estereotipos de los otros. Barcelona, Crítica, 2005.

CASHMORE, Ellis et BANTON, Michael (Coord.), Dictionary of race and ethnic relation. London, Routledge, 1996.

COELLO, Francisco, "Posesiones de Oceanía. Islas Marianas, Palaos y Carolinas". Atlas de España y sus Posesiones de Ultramar. En Atlas de España 
y sus posesiones de Ultramar. Diccionario Geográfico estadístico-histórico. Madrid, 1852.

DOUGLAS, Bronwen, "Rank, power, authority: a ressesment of traditional leadership in South Pacific Societies" En Journal of Pacific History, XIX, $n^{\circ} 1$, Taylor \& Francis, 1979, pp. 2-27.

DUBY, G, Mâle Moyen Age. De l'amour et autres essais. París, Flammarion, 1988

DUMONT D’URVILLE, J.S.C., "Sur les îles", en Bulletin de la Société de Géographie. $\mathrm{n}^{\circ} 105$, enero 1832, http://gallica.bnf.fr/ark:/12148/bpt6k37615z/ f6.image.

ELIZALDE PÉREZ-GRUESO, Ma Dolores, España en el Pacífico: la colonia de las islas Carolinas, 1885-1889. Madrid, CSIC-Instituto de Cooperación Iberoamericana, 1992.

ELIZALDE PÉREZ GRUESO, Ma Dolores "La investigación sobre Asia y el Pacífico en España, en las áreas de ciencias humanas y sociales", En Anuario de Asia y el Pacífico, n 1, Madrid, Instituto Elcano-CIDOB-Casa Asia, 2006, pp. 495- 506.

ERIKSON, Erik, Identidad, juventud y crisis. Buenos Aires, Paidós, 1968.

GOFF, Jaques le, L'imaginaire mediéval. Essais, París, Gallimard, 1985

GIENOW- HECHT, J.C.E., "Introduction: on the division of Knowledge and the community of thought: Culture and International history", En GIENOW-HECHT, J.C.E. et SCHUMACHER F. (edit), Culture and International History. New York, Berghahn Books, 2003, pp. 3-26

GREEN, R. C., "Near and Remote Oceania: disestablishing Melanesia in culture history" En PAWLEY, Andrew (edit.) Men and Half: essays in Pacific anthropology and etnobiology in honour of Ralph Bulmer.Auckland, Polynesian Society, 1991.pp. 491-502.

IGLER, David, The Great Sea: Pacific Worlds from Captain Cook to the Gold Rush, New York, Oxford University, 2013.

LEWIS, W. Martin et WIGEN Kären E., The myth of continents. A critique of Metageography. Berkeley,University of California Press, 1997.

LINDSAY, Lisa A., "The App.eal of transnational History", Perspectives Online. Vol. 50, n 9, diciembre 2012, pp. 48-49.

LUQUE TALAVÁN, M. et MANCHADO LÓPEZ, M. Ma (Coord.), Un Océano de Intercambio: Hispanoasia (1524-1898): Homenaje al profesor Leoncio Cabrero Fernández. Madrid, AECID- Ministerio de Asuntos Exteriores, 2007. MATSUDA, Matt K., Empire of love. Histories of France and the Pacific. Oxford, Oxford University, 2005. 
MATSUDA, M. K., "The Pacific", En American Historical Review, CXI, n" 3, University of Chicago, 2006. pp. 758-780, http://www2.kobe-u.ac. ip/ alexroni/TR\%202012/2012_4/The\%20Pacific.pdf.

MATSUDA, Matt K, Pacific Worlds. A History of seas, peoples and cultures. New York, Cambridge University, 2012.

MURGÍA LORES, A., "Durkheim y la cultura. Una lectura contemporánea" En Sociológica, n 50, México, Universidad Autónoma Metropolitana-Azcapotzalco, 2002, pp. 83-102.

MURILLO, Carlos, "La contribución de Kant a los estudios internacionales", En Praxis: revista del departamento de Filosofía, $n^{\circ} 58$, Universidad Nacional de Costa Rica, 2005, pp. 165-180.

NINKOVICH, F., "Interests and discourse in diplomatic history", Diplomatic History, 13 (2), 1989, pp. 135-161.

NIÑO, A., "Uso y abuso de las relaciones culturales en la política internacional",. En Ayer, n 75, 2009, pp. 25-61.

OLIVART, Ramón de Dalmau y de Olivart, Colección de los tratados, convenios y documentos internacionales celebrados por nuestros gobiernos con los Estados extranjeros desde el reinado de Doña Isabel II hasta nuestros días, XI,Madrid, Librería Fernado Fé, 1897-1899.

PASTOR y SANTOS, E., Territorios de soberanía española en la Oceanía. Madrid, CSIC, 1950.

PEARSON, F.S. et ROCHESTER, J.M., Relaciones Internacionales. Situación global en el siglo XXI. Bogotá, Ed. MacGraw-Hill, 2000.

PEREIRA, Juan Carlos (Coord.), Historia de las Relaciones Internacionales Contemporáneas. Barcelona, Ariel, 2009 (2edición).

RIENZI, Domeny di, Océanie oú cinquième parte du monde comprenant l'archipel d'Asie, I'Australasie et la Polinésie (Ou continent de la NouvelleHollande et les îles du Gran Ocean), Paris, Desray-Goujon, 1814.

SCHURZ, William Lytle, "The Spanish Lake", En The Hispanic American Historical Review, V, n' 2, Duke University, 1922, pp. 181-194.

SPATE, O.H.K, The Spanish Lake: The Pacific since Magellan, I. Australia, ANU Press, 1979. [traducida al castellano por Casa Asia, 2006].

TCHERKÉZOFF, Serge, "A long and unfortunate voyage towards the "Invention" of Melanesia/Polynesia distinction 1595-1832" En The Journal of Pacific History, XXXVIII, n 2. Taylor \& Francis, 2003, pp. 175-196.

THOMAS, N., "The force of ethnology: origins and significance of the Melanesia/Polinesia división" En Current Anthropology, XXX, n 1. Chicago University: 1989. pp. 27-41. 
WALLACE, Alfred Rusell, The Malay archipelago, The land of the orangutan, and the bird or paradise. A narrative of travel, with sketches of man and nature. London, Macmillan, 1869, http://www.papuaweb.org/dlib/bk/ wallace/book.html.

WOODWARD, David et LEWIS, Malcom, "Concluding Remarks" En WOODWARD, David et LEWIS, Malcom (Coord.), The history of cartography, vol.II, libro III, Cartography in the traditional African, American, Artic, Australian and Pacific societies. Chicago- Londres, University Chicago, 1998, pp. 237-541. 